\title{
Control of a Photovoltaic Array Interfacing Current-Mode-Controlled Boost Converter based on Virtual Impedance Emulation
}

\author{
Andoni Urtasun, Member, IEEE, Javier Samanes, Student member, IEEE, Ernesto L. Barrios, \\ Member, IEEE, Pablo Sanchis, Senior Member, IEEE, and Luis Marroyo, Member, IEEE
}

\begin{abstract}
Due to the non-linear characteristics of a photovoltaic (PV) array, its regulation is highly dependent on the operating point. Focusing on a dc/dc boost converter, this paper first shows how the PV voltage and inductor current controls are affected by the PV array. It then proposes to emulate an impedance virtually connected to the PV array, making it possible to greatly improve the control robustness. Thanks to the proposed strategy, the crossover frequency variation for the whole operating range is reduced from 42 times for the traditional control to 3.5 times when emulating parallel resistance or to 1.4 times when emulating series and parallel resistances, all with simple implementation. Experimental results with a commercial PV inverter and a 4-kWp PV array validate the theoretical analysis and demonstrate the superior performance of the proposed control.
\end{abstract}

Index Terms-Dynamic resistance, photovoltaic converters, robust control, small-signal modeling, voltage control.

\section{INTRODUCTION}

$\mathrm{P}$ HOTOVOLTAIC systems are undergoing continuous expansion and development, both in grid-connected and stand-alone applications. In order to obtain the maximum power available from the PV array, the PV system is usually interfaced by a power converter which controls the input voltage according to the Maximum Power Point Tracking (MPPT) algorithm [1]-[3]. In some situations, however, it may be necessary to reduce the PV power to below the maximum power, which is achieved by modifying the input voltage towards the open-circuit area [4], [5], or the short-circuit area [6]. As a result, the voltage regulation must be designed to attain predetermined closed-loop performance in the whole operating range [7].

At the same time, it is widely known that the photovoltaic array exhibits a nonlinear I-V curve, which causes the regulation performance to change with the operating point. In

Manuscript received February 6, 2018; revised April 14, 2018; accepted June 24, 2018. This work was supported in part by the Spanish State Research Agency (AEI) and FEDER-UE under grant DPI201680641-R. small-signal analysis, this nonlinear effect is represented by dynamic resistance, which is obtained from the slope of the I-V curve, and varies with PV voltage, irradiance and cell temperature [8]. In recent years, the input capacitor size has been reduced in order to cut costs and improve reliability [9]. As a result, the PV nonlinear influence has increased in importance and can lead to great variations in dynamics and even put stability at risk [10]-[12]. In turn, this issue complicates the implementation of fast and robust MPPT algorithms.

The effect of dynamic resistance on the control of a boost converter has been analyzed in the literature. In [13], the authors regulate the PV voltage through the duty cycle, i.e., without an inner current loop. These control schemes are usually applied to small PV generators (e.g., $50 \mathrm{~W}$ in [13]). In these systems, the influence of dynamic resistance results in a highly variable damping factor of the duty cycle to voltage transfer function. However, the undamped natural frequency hardly changes, and the system can be easily controlled with a second-order controller with no appreciable changes in the regulation performance [13], [14].

For higher power boost converters (typically over $1 \mathrm{~kW}$ ), the PV voltage is usually controlled through an inner inductor current loop. The cascaded control avoids current transients and reduces failure rates. In these systems, the influence of dynamic resistance makes the voltage regulation become much slower than the design specifications, especially when using small input capacitors [15].

In order to use small ceramic/film capacitors and, at the same time, maintain constant dynamic performance, different solutions have been proposed in the literature. As a first attempt, adaptive voltage control was proposed [15]-[17]. According to this method, the dynamic resistance is first estimated from measured variables of the converter and then the controller is continuously adapted on the basis of this estimation. While achieving satisfactory results, this approach is complex to implement as it requires a complicated algorithm to estimate the dynamic resistance and the controller parameters need to be modified in real time. Furthermore, the control

A. Urtasun, J. Samanes, E. L. Barrios, P. Sanchis and L. Marroyo are with the Department of Electrical, Electronic and Communications Engineering, Public University of Navarre (UPNA). The corresponding author is Andoni Urtasun (email: andoni.urtasun@unavarra.es). 
presented in [15] is only applicable to two-stage single-phase PV inverters whereas the control presented in [16] and [17] injects a harmonic current into the system and requires a fast inner current loop.

As an alternative to adaptive control for the input voltage loop, some authors have proposed disturbance observer-based control [18], [19]. This method estimates lumped uncertainty and disturbance, causing the system to deviate from the nominal plant, and cancels it, making the main controller see the nominal plant. However, since an ideal estimation is obviously unfeasible, the robustness is not absolute. According to the results shown in [18] and [19], as the implementation complexity increases, the control robustness improves. In [18], when the control action consists of 3 PI controllers, the crossover frequency variation ranges from 9.5 to $31.8 \mathrm{~Hz}(3.3$ times) and, when using 2 PI controllers, it ranges from 2.4 to $43.8 \mathrm{~Hz}$ (18.2 times). With regard to [19], the final control implementation comprises only one PI controller. As a result, the method is expected to experience a large dynamic variation when operating with small input capacitors, similarly to the traditional control.

In this paper, a different approach, based on virtual impedance emulation, is adopted. The impedance emulation concept is employed with different purposes, such as stabilization of constant power loads, power flow control, harmonic compensation and fault ride-through [20]-[22]. However, to the best of the authors' knowledge, its use to reduce the dynamic variability has been hardly reported. In [23] and [24], an impedance in parallel with a battery is emulated to improve the robustness of the voltage regulation. This system is completely different to the studied PV arrays since the battery voltage control is much slower and the impedance extremely lower. As a result, the effect of the battery impedance on the inner current loop can be disregarded and the best solution consists of emulating a parallel RL impedance [23]. A first attempt to extend this method to PV arrays was developed in [25], where a parallel resistance emulation is selected. In this work, the effect of the PV array on the inner current loop is also disregarded for the design of the virtual resistance. However, since the PV dynamic resistance is much higher than the battery impedance, this simplification leads to a non-optimal solution.

This paper takes into account the PV array influence on both current and voltage loops. As a result, the virtual resistance value can be more accurately obtained, improving the dynamic response with regard to [25]. Furthermore, unlike in [23]-[25], it is then proposed to further improve the control performance by emulating series and parallel impedances. Among the different possibilities, the use of positive parallel resistance and negative series resistance is proposed. This solution is very simple to implement and results in almost full robustness, limiting the crossover frequency variation range from 42 to 60 $\mathrm{Hz}$ (only 1.4 times). Moreover, in this case, unlike in [25], experimental results are obtained and validate the proposed methods.

This paper is organized as follows. Section II presents the system analyzed, including the control structure and the PV array model. Section III derives the model of the inner current loop, taking into account the influence of dynamic resistance. Then, in section IV, the PV voltage regulation is analyzed for three different control methods: the traditional control with a PI controller, the proposed method with parallel impedance emulation, and the proposed method with series and parallel impedance emulation. Experimental results are given in section V. Finally, conclusions of this work are drawn in section VI.

\section{SYSTEM DESCRIPTION}

The system analyzed is shown in Fig. 1, consisting of a photovoltaic array, an input capacitor, $C$, a boost converter, and a bus capacitor, $C_{d c}$. The output can vary depending on the application, such as a voltage-fed inverter or a microgrid DC bus.

The PV voltage regulation is carried out by means of cascaded feedback loops, where the inner loop controls the inductor current. The control structure is shown in Fig. 2, where $d$ is the IGBT duty cycle, $i_{L}^{*}$ represents the reference current and $v_{p v}^{*}$ the reference voltage. As can be observed in the figure, the measured variables are $i_{L, f}, v_{p v, f}$ and $v_{d c, f}$, and are used for the regulation.

The features of the boost converter and the PV array used throughout the paper are given in Table I and Table II, respectively.

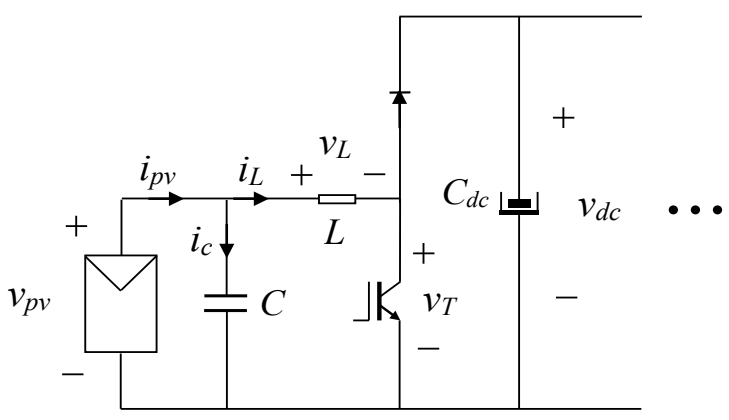

Fig. 1. Photovoltaic array connected to a boost converter.

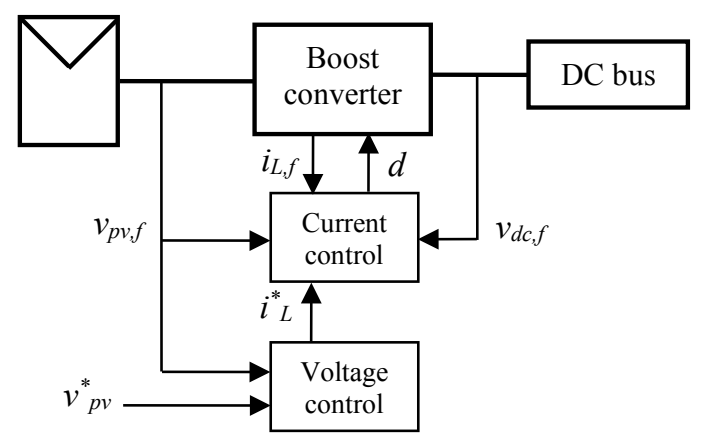

Fig. 2. Control structure of the boost converter. 
TABLE I

FEATURES OF THE DC/DC BOOST CONVERTER

\begin{tabular}{ll}
\hline \hline Parameter & Value \\
\hline Nominal power & $5000 \mathrm{~W}$ \\
Input capacitor $C$ & $40 \mu \mathrm{F}$ \\
Boost inductor $L$ & $750 \mu \mathrm{H}$ \\
Switching frequency $f_{s}$ & $16 \mathrm{kHz}$ \\
PV voltage loop sampling time $T_{s v}$ & $250 \mu \mathrm{s}$ \\
Inductor current loop sampling time $T_{s i}$ & $125 \mu \mathrm{s}$ \\
Time constant of the PV voltage sensing $\tau_{v}$ & $80 \mu \mathrm{s}$ \\
Time constant of the PV current sensing $\tau_{i}$ & $80 \mu \mathrm{s}$ \\
Design crossover frequency of the voltage control $f_{c v}$ & $60 \mathrm{~Hz}$ \\
Design crossover frequency of the current control $f_{c i}$ & $500 \mathrm{~Hz}$ \\
Bus voltage & $340 \mathrm{~V}$ \\
\hline \hline
\end{tabular}

TABLE II

SPECIFICATIONS OF THE PV ARRAY AT STC, FORMED BY 4 STRINGS OF 12 BP585 MODULES

\begin{tabular}{ll}
\hline \hline Parameter & Value \\
\hline Peak power & $4080 \mathrm{~W}$ \\
MPP voltage $V_{m p p}$ & $216 \mathrm{~V}$ \\
MPP current $I_{m p p}$ & $18.9 \mathrm{~A}$ \\
Open-circuit voltage $V_{o c}$ & $264 \mathrm{~V}$ \\
Short-circuit current $I_{s c}$ & $20 \mathrm{~A}$ \\
Equivalent series resistance & $0.85 \Omega$ \\
Equivalent shunt resistance & $736 \Omega$ \\
Cells connected in series in a module $N_{s}$ & 36 \\
Ideality factor $m$ & 1 \\
\hline \hline
\end{tabular}

As the PV array exhibits nonlinear behavior, it is usual to employ small-signal analysis so that linear modeling techniques can be used. The PV current depends on the PV voltage through the characteristic I-V curve, $i_{p v}=\mathrm{f}\left(v_{p v}\right)$. From this expression, small-signal variations of the PV current can be obtained as

$$
\hat{i}_{p v}=\left.\frac{\partial i_{p v}}{\partial v_{p v}}\right|_{V p v, I p v, G, T} \cdot \hat{v}_{p v},
$$

where the derivate is evaluated for the DC operating point in terms of PV voltage $V_{p v}, \mathrm{PV}$ current $I_{p v}$, irradiance $G$ and cell temperature $T$.

Taking into account the definition of the dynamic resistance, $R_{p v}$, (1) can be rewritten as [12]

$$
R_{p v}=-\left(\left.\frac{\partial i_{p v}}{\partial v_{p v}}\right|_{V p v, I p v, G, T}\right)^{-1} \Rightarrow \quad \hat{i}_{p v}=-\frac{\hat{v}_{p v}}{R_{p v}} .
$$

This equation shows that the small-signal PV current variation due to the small-signal PV voltage variation depends on the dynamic resistance. Resistance $R_{p v}$ is highly variable as a function of the operating point and becomes smaller for high voltages, high irradiances and high temperatures. As shown in [15], for typical PV arrays in this power range, the dynamic resistance variation can be considered from $R_{p v}=1 \Omega$, corresponding to an operating point at open-circuit voltage (OCV) to $R_{p v}=100 \Omega$, for a voltage below MPP, towards shortcircuit.

\section{MODELING OF THE INNER CURRENT LOOP}

From Fig. 1 and considering average values in a switching period, the inductor voltage $v_{L}$ can be determined as

$$
v_{L}=L \cdot \frac{d i_{L}}{d t}=v_{p v}-v_{T}=v_{p v}-(1-d) \cdot v_{d c} .
$$

In order to reduce the influence of input and output impedances on the current control, the measured variables $v_{d c, f}$ and $v_{p v, f}$ are used as feed-forward compensations [26]. Since a large capacitor is used at the output, it is possible to assume that the output voltage compensation is ideal, in contrast to the input voltage compensation [18]. Thus, the input impedance must be taken into account which, in small-signal and using (2), can be obtained as

$$
Z_{p v}(s)=-\frac{\hat{v}_{p v}}{\hat{i}_{L}}=\frac{1}{C \cdot s+1 / R_{p v}}=\frac{R_{p v}}{C \cdot R_{p v} \cdot s+1} .
$$

The control loop for the current control is shown in Fig. 3, where $v^{*}{ }_{L}$ is the reference inductor voltage, $v^{*}{ }_{T}$ the reference switch voltage, $C_{i}$ represents the current controller, $S_{i}$ the sampling and computational time delay, $H_{v}$ the voltage sensing and $H_{i}$ the current sensing.

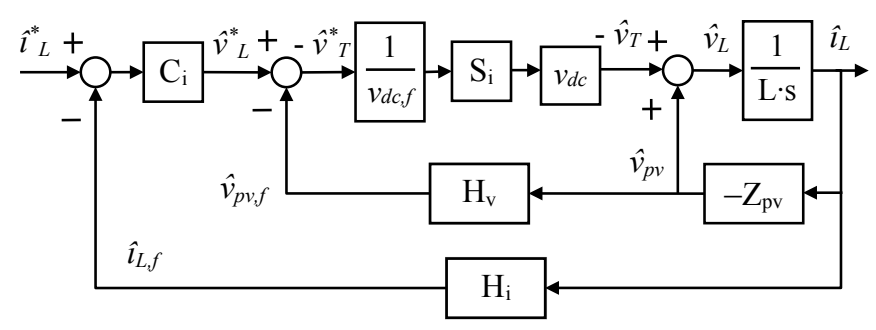

Fig. 3. Inductor current control loop.

The sensing transfer functions can be modeled as

$$
H_{i}(s)=\frac{1}{\tau_{i} \cdot s+1}, \quad H_{v}(s)=\frac{1}{\tau_{v} \cdot s+1},
$$

where $\tau_{i}$ and $\tau_{v}$ are the time constants of the inductor current and $\mathrm{PV}$ voltage sensing, respectively.

Two effects must be considered in the transfer function $S_{i}$, namely the zero-order hold and the computation delay. Being $T_{s i}$ the sampling time, $S_{i}$ can be approximated as [27]

$$
S_{i}(s)=\frac{1-0.5 \cdot T_{s i} \cdot s}{\left(1+0.5 \cdot T_{s i} \cdot s\right)^{2}}
$$

From Fig. 3, the plant seen by the current controller, $Y_{e q}$, can be determined as

$$
Y_{e q}(s)=\frac{\hat{i}_{L}}{\hat{v}_{L}^{*}}=\frac{S_{i}}{L \cdot s+Z_{p v} \cdot\left(1-H_{v} \cdot S_{i}\right)} .
$$

As can be observed in this expression, ideal compensation $\left(H_{v} \approx 1\right.$ and $\left.S_{i} \approx 1\right)$ or small $Z_{p v}$ impedance (large C) yield $Y_{e q} \approx S_{i} / L s$, thus rejecting the dynamic resistance influence on the current control. However, for current input capacitor values and taking into account that, in real applications, the compensation rapidity will be limited by the microprocessor, the effect of the large $R_{p v}$ variation range cannot be neglected.

In order to achieve a high crossover frequency, the current controller is usually selected as a proportional controller, $C_{i}=K_{P}$. As traditionally carried out, its gain is selected here 
assuming that the input impedance has no effect, i.e. for $Y_{e q}=S_{i} / L s$, and for a crossover frequency $f_{c i}=500 \mathrm{~Hz}$, which gives a phase margin $\Phi_{m i}=42^{\circ}$.

From Fig. 3 and considering (7), the closed-loop transfer function for the inductor current control can be obtained as

$$
G_{i c l}(s)=\frac{\hat{i}_{L}}{\hat{i}_{L}^{*}}=\frac{C_{i} \cdot Y_{e q}}{1+C_{i} \cdot Y_{e q} \cdot H_{i}} .
$$

The Bode plot of $G_{i c l}$ is shown in Fig. 4 for the ideal compensation of the input impedance and three real operating points: at $\mathrm{OCV}\left(R_{p v}=1 \Omega\right)$, near MPP $\left(R_{p v}=10 \Omega\right)$ and below MPP voltage $\left(R_{p v}=100 \Omega\right)$. As can be observed, dynamic resistance has a substantial influence on the current closed-loop, particularly when operating with high $R_{p v}$ values, for which the bandwidth is reduced. Conversely, keeping in mind the outer voltage loop, it is worth noting that the phase remains above $45^{\circ}$ for a large frequency range.

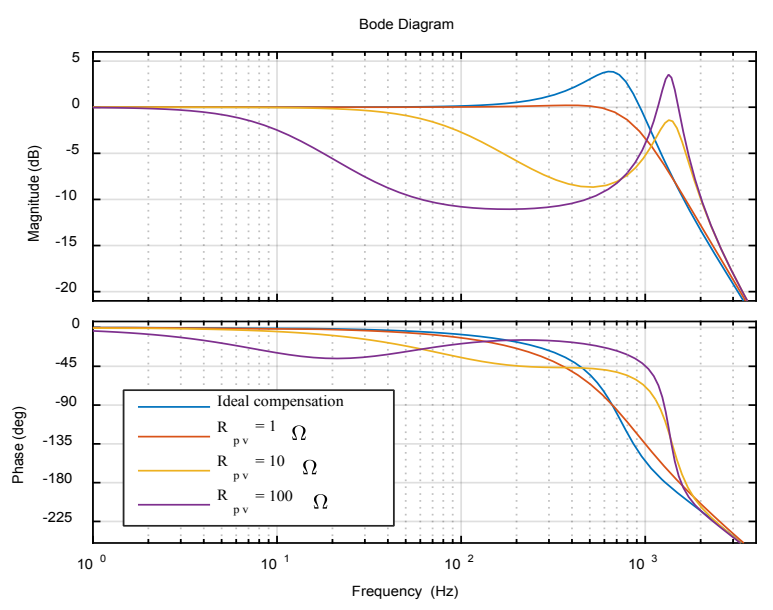

Fig. 4. Current closed-loop $G_{i c l}$ for ideal compensation and three different operating points $\left(R_{p v}=1 \Omega, R_{p v}=10 \Omega\right.$ and $\left.R_{p v}=100 \Omega\right)$.

\section{Voltage Regulation}

\section{A. Traditional Control}

Once the current loop is designed, the voltage control loop is shown in Fig. 5, where $C_{v}$ represents the voltage controller and $S_{v}$ the sampling and computational time delay.

Being $T_{s v}$ the sampling time, $S_{v}$ can be approximated as [27]

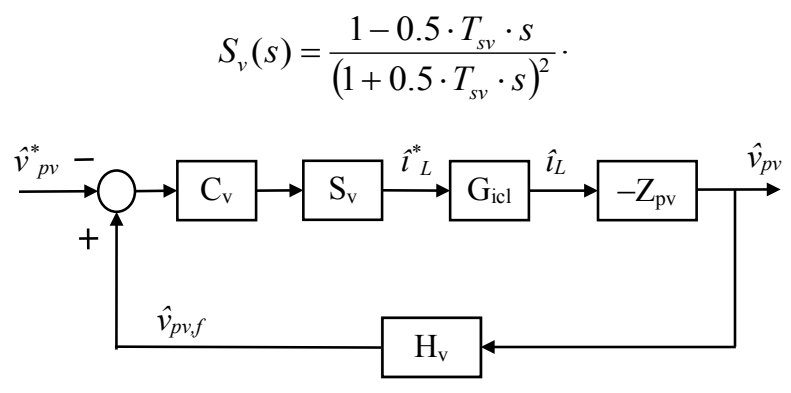

Fig. 5. PV voltage control loop for the traditional control.

In this control loop, the input impedance $Z_{p v}$ [see (4)] appears in the forward path. To see how this impedance behaves, it is plotted in Fig. 6 for $C=40 \mu \mathrm{F}$ and the previous three operating points: $R_{p v}=1 \Omega, R_{p v}=10 \Omega$ and $R_{p v}=100 \Omega$. As can be observed in the figure, $Z_{p v}$ is highly variable depending on the operating point. Focusing on $60 \mathrm{~Hz}$, which is a suitable crossover frequency for this control, the plant impedance $Z_{p v}$ varies from $1 \Omega$ near OCV to $55 \Omega$ below MPP.

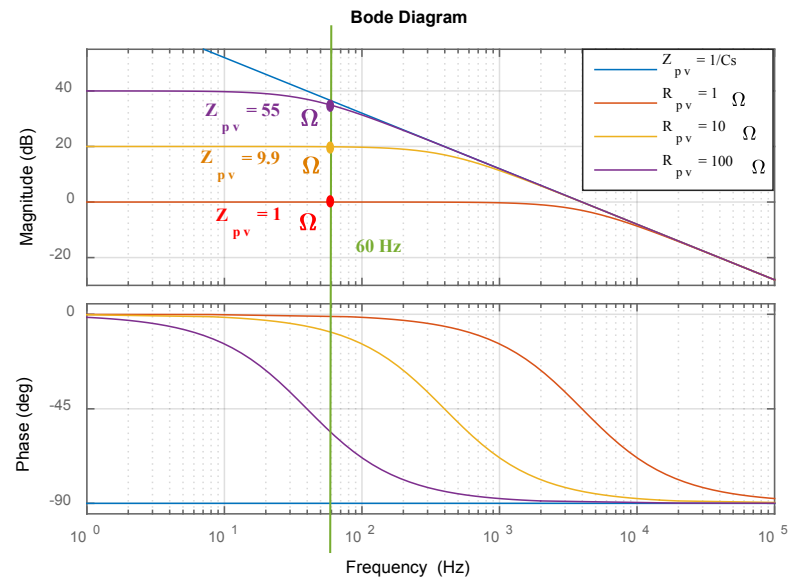

Fig. 6. Input impedance $Z_{p v}$ for $R_{p v} \rightarrow \infty\left(Z_{p v}=1 / C s\right)$ and three different operating points $\left(R_{p v}=1 \Omega, R_{p v}=10 \Omega\right.$ and $\left.R_{p v}=100 \Omega\right)$.

In order to avoid voltage steady-state error, a PI controller is typically used in the scheme of Fig. 5. Its parameters have been traditionally obtained assuming that the dynamic resistance has no influence on the system, hence for $G_{i c l}=1$ and $Z_{p v}=1 / C s$ [28], [29]. This is adopted in this section for a crossover frequency $f_{c v}=60 \mathrm{~Hz}$ and a phase margin $\Phi_{m v}=40^{\circ}$.

Figure 7 shows the compensated open loop for the ideal case with $G_{i c l}=1$ and $Z_{p v}=1 / C s$ and for three different operating points $\left(R_{p v}=1 \Omega, R_{p v}=10 \Omega\right.$ and $\left.R_{p v}=100 \Omega\right)$. As can be observed, even for high dynamic resistances, where the assumption $Z_{p v}=1 / C s$ is valid, the crossover frequency becomes slower than desired. This is due to having neglected the effect of dynamic resistance on the inner closed-loop, whose gain is actually lower than 1 at $f_{c v}=60 \mathrm{~Hz}$ (see Fig. 4). Furthermore, for smaller $R_{p v}$ values, although the effect of the inner closed-loop diminishes, impedance $Z_{p v}$ drastically decreases (see Fig. 6), leading to a very slow control. Accordingly, although $f_{c v}=60 \mathrm{~Hz}$ was desired, the actual crossover frequency varies from $0.59 \mathrm{~Hz}$ to $25 \mathrm{~Hz}$ for the whole operating range, i.e. a ratio of 42 times.

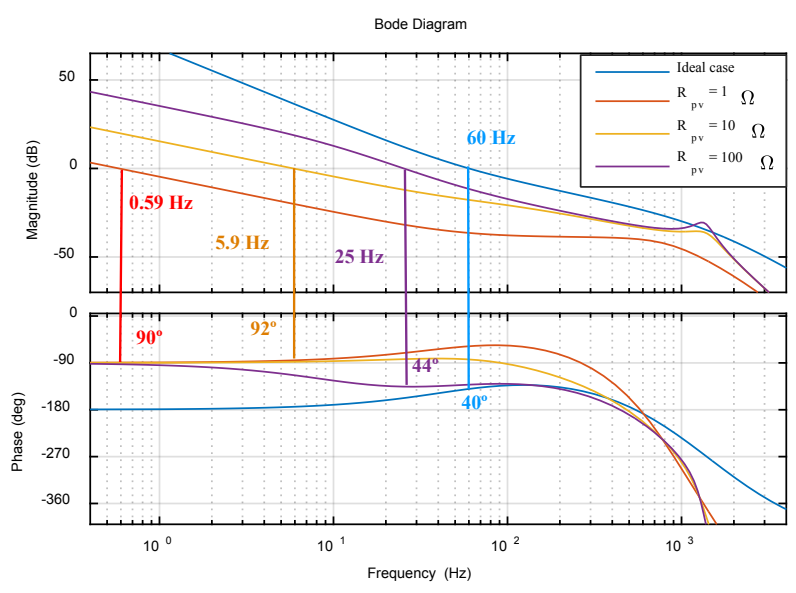

Fig. 7. Compensated open-loop $C_{v} \cdot S_{v} \cdot G_{i c l} \cdot Z_{p v} \cdot H_{v}$ for the ideal case with $G_{i c l}=1$ and $Z_{p v}=1 / C s$ and three different operating points $\left(R_{p v}=1 \Omega, R_{p v}=10 \Omega\right.$ and $R_{p v}=100 \Omega$ ). 
The analysis for the traditional control was validated by means of simulation with the PSIM software. The simulation model includes the PV array at STC, with features as shown in Table II, the boost converter, with features as shown in Table I, and a single-phase inverter connected to a low-voltage grid. In Fig. 8, the PV voltage and the dynamic resistance $R_{p v}$ are represented for downward steps in the PV voltage reference $V_{p v_{-} \text {ref }}$ from $260 \mathrm{~V}$, close to OCV $\left(V_{o c}=264 \mathrm{~V}\right)$, to $190 \mathrm{~V}$, well below the MPP voltage $\left(V_{m p p}=216 \mathrm{~V}\right)$. As predicted by the previous analysis, the control response is highly variable depending on the operating point and becomes too slow in the whole operating range, especially near OCV.

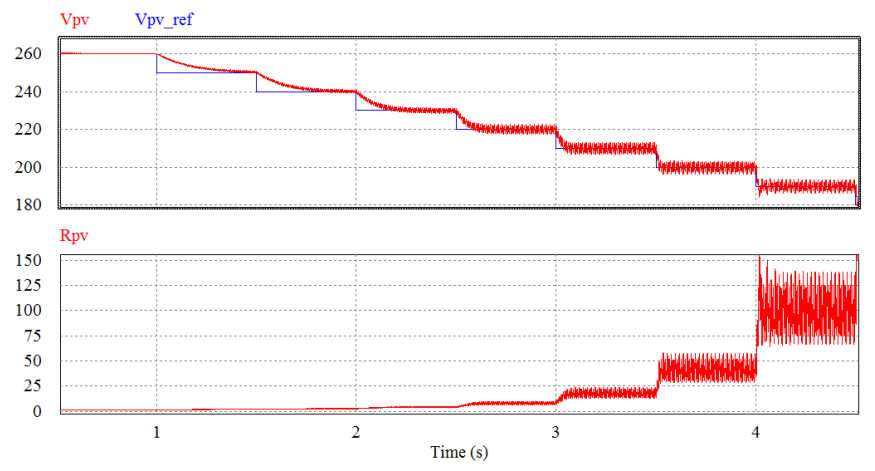

Fig. 8. Simulation of the PV voltage regulation for the traditional control.

\section{B. Parallel Impedance Emulation (PIE)}

A straightforward strategy to reduce the influence of the dynamic resistance variation would be to add an impedance in parallel with the PV array, such as a small resistance or a large capacitance. If this impedance is small enough around the frequencies of concern, then the system would behave as this known impedance, and thus the plant variability would be completely removed. Although the required impedance is obviously too small for real applications and would result in high cost (capacitor) or power losses (resistor), it can be emulated thanks to the inner current loop. The voltage control loop for the real impedance is represented in Fig. 9(a), where $Z_{\text {real }}$ is the real impedance, and $i_{Z}$ and $i_{R C}$ the currents flowing through that impedance and through the combination of the PV array and the input capacitor, respectively. Similarly, the voltage loop for the virtual impedance is shown in Fig. 9(b), where $Z_{p}$ is the virtual parallel impedance, $i_{z p}$ the current flowing through that impedance, and $i_{v}$ the virtual current. It is important to notice that, in contrast to the real impedance, in this case the impedance does not modify the inductor current in steady-state and thus the converter current is similar to the original one.

By comparing the figures, it can be observed that, in reality, the impedance emulation is not exact because the measured voltage is used instead of the real voltage, and the reference current is modified instead of the real inductor current. More precisely, from Fig 9(b), the equivalent impedance, $Z_{e q}$, seen by the controller, can be obtained as

$$
Z_{e q}(s)=-\frac{\hat{v}_{p v}}{\hat{i}_{v}}=\frac{S_{v} \cdot G_{i c l} \cdot Z_{p v}}{1+S_{v} \cdot G_{i c l} \cdot H_{v} \cdot Z_{p v} / Z_{p}} .
$$
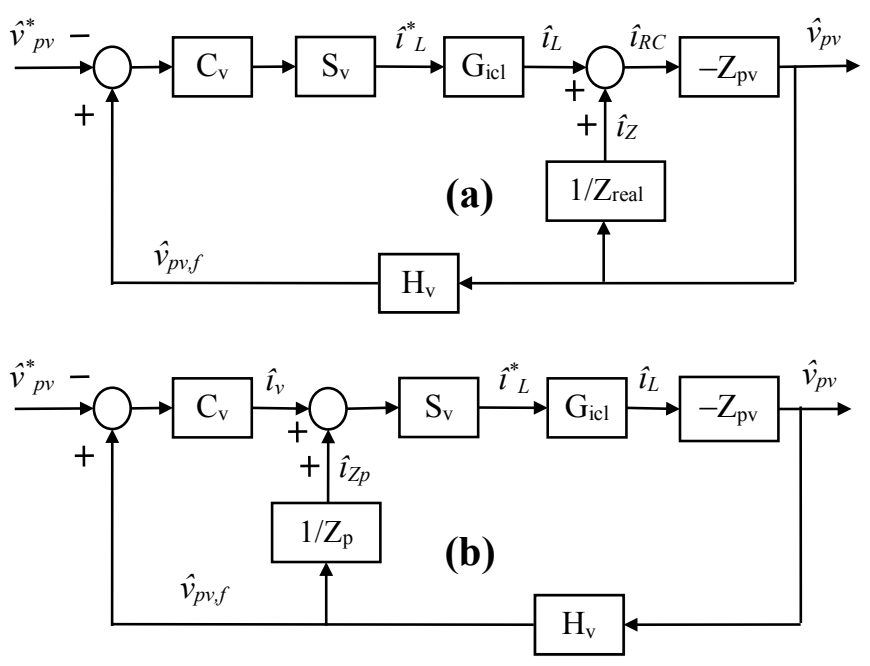

Fig. 9. PV voltage control loops: (a) with a real parallel impedance, $Z_{\text {real }}$, (b) with an emulated parallel impedance, $Z_{p}$.

From this equation and for ideal emulating conditions $\left(S_{v}=1, H_{v}=1\right.$ and $\left.G_{i c l}=1\right)$, the equivalent impedance seen by the controller becomes

$$
Z_{e q}(s)=-\frac{\hat{v}_{p v}}{\hat{i}_{v}} \approx \frac{Z_{p v} \cdot Z_{p}}{Z_{p v}+Z_{p}}=Z_{p v} / / Z_{p} .
$$

An important issue at this point is how to design the virtual impedance. As already suggested, its value should be low enough around the crossover frequency so that dynamic resistance $R_{p v}$ has no influence. However, since it is located in the feedback path [see Fig. 9(b) and (10)], its minimum value is limited in order to avoid Right-Half-Plane (RHP) poles in equivalent impedance $Z_{e q}$. According to the generalized Bode criterion applied to $Z_{e q}[30]$, if all $-180^{\circ} \pm \mathrm{k} \cdot 360^{\circ}$ phase crossings of the open loop Bode plot have negative gain (i.e. lower than $0 \mathrm{~dB}$ ), no RHP poles will appear in closed-loop impedance $Z_{\text {eq. }}$. Thus, this criterion can be used to set the minimum gain of virtual impedance $Z_{p}$ once the impedance type has been chosen. Depending on the system, this minimum value could be a limitation on the effectiveness of the method.

Although other impedance types could be used for this application [23], for simplicity of implementation, a resistance is selected here as virtual impedance, $Z_{p}=R_{p}$. In order to set its value, the open loop Bode plot for the impedance emulation not including $Z_{p}$, that is $S_{v} \cdot G_{i c l} \cdot H_{v} \cdot Z_{p v}$, must be analyzed. This is shown in Fig. 10 for our case study. As can be observed, the highest gain at $-180^{\circ}$ phase crossing is $7.53 \mathrm{~dB}$, for an operating point with $R_{p v}=100 \Omega$. As a result, a virtual resistance $R_{p}>2.38 \Omega$ is required to guarantee stability, and $R_{p}=3 \Omega$ is chosen to allow for a certain gain margin.

Once the virtual impedance is selected, equivalent impedance $Z_{e q}$ can be determined by means of (10), and its Bode plot is shown in Fig. 11. As can be observed, at low frequencies, $Z_{e q}$ behaves as an impedance $Z_{p v} / / R_{p}$ according to (11), which is similar to the resistance $R_{p v} / / R_{p}$. As a result, equivalent impedance around the crossover frequencies roughly ranges from a minimum value of $R_{p v, \text { min }} / / R_{p}=0.75 \Omega$ to a maximum value of $R_{p v, \min } / / R_{p}=2.91 \Omega \approx R_{p}$, greatly reducing the plant variability seen by the voltage controller. 


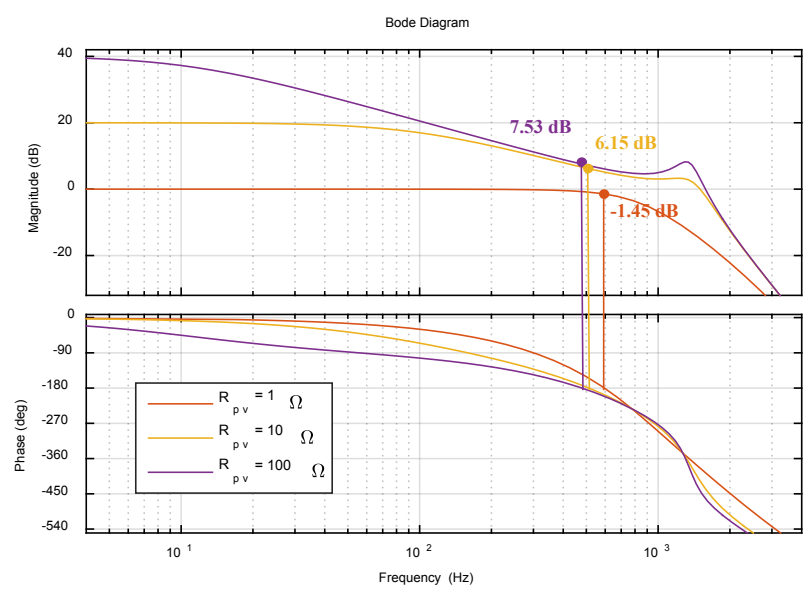

Fig. 10. Open-loop for PIE not including $Z_{p}$, i.e. $S_{v} \cdot G_{i c l} \cdot Z_{p v} \cdot H_{v}$, for three different operating points $\left(R_{p v}=1 \Omega, R_{p v}=10 \Omega\right.$ and $\left.R_{p v}=100 \Omega\right)$.

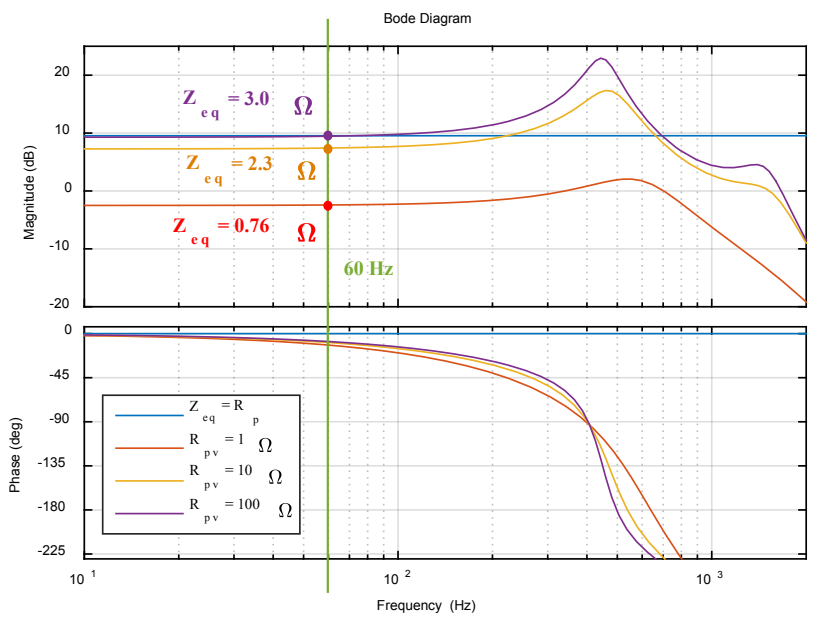

Fig. 11. Equivalent impedance seen by the voltage controller with PIE, $Z_{e q}$, for the ideal case where $Z_{e q}=R_{p}$ and for three different operating points $\left(R_{p v}=1 \Omega\right.$, $R_{p v}=10 \Omega$ and $R_{p v}=100 \Omega$ ).

To conclude, voltage controller $C_{v}$ must be designed. It is selected as an integrator to avoid steady-state error, together with a pole to increase the gain margin. It is expressed as

$$
C_{v}(s)=\frac{K_{i}}{s \cdot\left(s / \omega_{p}+1\right)},
$$

where $K_{i}$ is the controller gain and $\omega_{p}$ is the controller pole.

The compensated open-loop is shown in Fig. 12, where the voltage controller is designed to obtain a crossover frequency $f_{c v}=60 \mathrm{~Hz}$ and a phase margin $\Phi_{m v}=50^{\circ}$ for $R_{p v}=100 \Omega$. As can be observed, for high dynamic resistances, the voltage response agrees with the specifications whereas, for very low dynamic resistances, the control becomes slower. In any case, comparing this performance with the traditional control (see Fig. 7), it is clear that the dynamic behavior has been greatly improved in all operating points. In other words, the crossover frequency range has been reduced, now varying from $17 \mathrm{~Hz}$ to $60 \mathrm{~Hz}$, i.e. a ratio of 3.5 times.

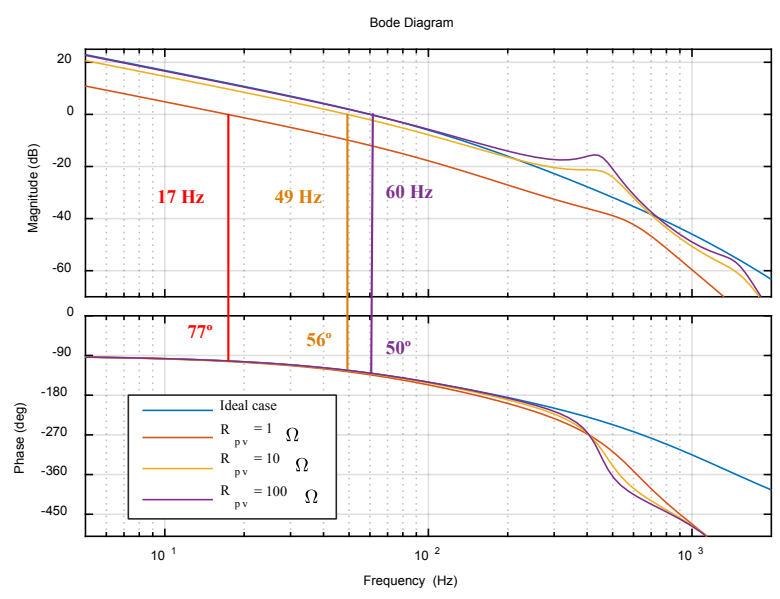

Fig. 12. Compensated open loop for the PV voltage regulation with PIE, $C_{v} \cdot Z_{e q} \cdot H_{v}$, for the ideal case where $Z_{e q}=S_{v} \cdot R_{p}$ and for three different operating points $\left(R_{p v}=1 \Omega, R_{p v}=10 \Omega\right.$ and $\left.R_{p v}=100 \Omega\right)$.

In a previous work [25], this analysis was carried out by assuming that the dynamic resistance has no effect on the inner current loop. As a result, the minimum resistance to be emulated is overestimated, which leads to a higher dynamic variability. Specifically, by using the methodology presented in [25] applied to our case study, the selected virtual resistance should be $R_{p}=6.7 \Omega$, resulting in a crossover frequency variation range from $8.7 \mathrm{~Hz}$ to $60 \mathrm{~Hz}$, i.e. a ratio of 6.9 times.

The simulation presented in Fig. 8 is now carried out for the proposed control with PIE and $R_{p}=3 \Omega$. Similarly, the results are shown in Fig. 13 for downward steps in the PV voltage reference $V_{p v_{-}}$ref, addressing the whole operating range (note the difference in the time scale compared with Fig. 8). As can be observed, the control is fast and less variable for all operating points.

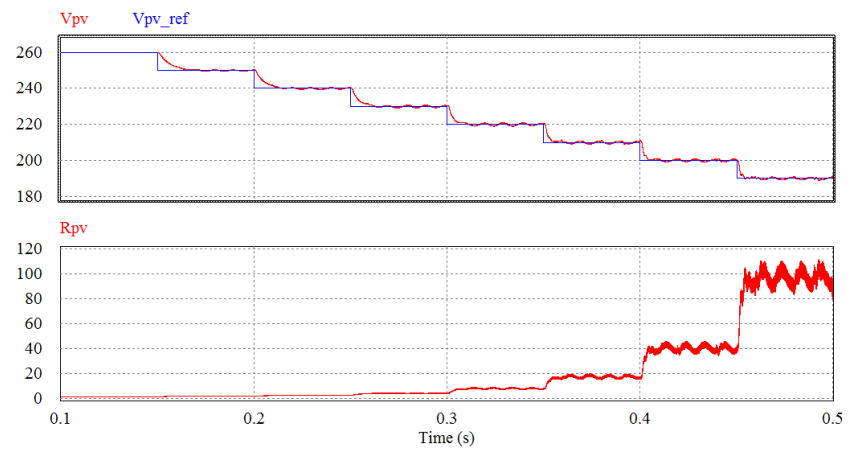

Fig. 13. Simulation of the PV voltage regulation for the proposed control with PIE.

By using the parallel resistance emulation, the control performance has been greatly improved with a very simple implementation. Nevertheless, the minimum $R_{p}$ which it is possible to emulate due to stability issues, restricts the dynamic behavior for very low $R_{p v}$ values. On the other hand, in order to track fast irradiance variations, MPPT algorithms are becoming faster [31], [32]. Thus, in order to further increase the voltage control robustness, another emulation technique is proposed in the next section. 


\section{Series and Parallel Impedance Emulation (SPIE)}

In order to further reduce the impedance variation seen by the controller, the parallel impedance-based strategy presented in the previous section can be combined with the emulation of an impedance in series with the PV array. This results in the equivalent circuit shown in Fig. 14(a), where $Z_{s}$ is the virtual series impedance, $v_{Z s}$ the voltage drop across that impedance and $v_{v}$ the virtual voltage. To understand how this equivalent circuit can be reproduced, the voltage loop for SPIE is represented in Fig. 14(b). As can be observed in this figure, only the PV voltage and inductor current measurements, both of which are available, are required for the emulation.

In this case, the equivalent impedance seen by the controller can be obtained from Fig. 14(b) as

$$
Z_{e q}(s)=-\frac{\hat{v}_{p v}}{\hat{i}_{v}}=\frac{S_{v} \cdot G_{i c l} \cdot Z_{p v}}{1+S_{v} \cdot G_{i c l} \cdot\left(H_{v} \cdot Z_{p v}+H_{i} \cdot Z_{s}\right) / Z_{p}} .
$$

From (13) and for ideal emulation conditions $\left(S_{v}=1, H_{v}=1\right.$, $H_{i}=1$ and $\left.G_{i c l}=1\right)$, the equivalent impedance seen by the controller becomes (14). This equation can also be obtained from the ideal equivalent circuit shown in Fig. 14(a).

$$
Z_{e q}(s)=-\frac{\hat{v}_{p v}}{\hat{i}_{v}} \approx \frac{Z_{p v} \cdot Z_{p}}{Z_{p v}+Z_{s}+Z_{p}} .
$$

From (14), if series and parallel impedances are emulated such that $Z_{s}=-Z_{p}$, the equivalent impedance variation completely disappears. In other words,

$$
Z_{s}=-Z_{p} \Rightarrow Z_{e q}(s)=-\frac{\hat{v}_{p v}}{\hat{i}_{v}} \approx Z_{p} .
$$
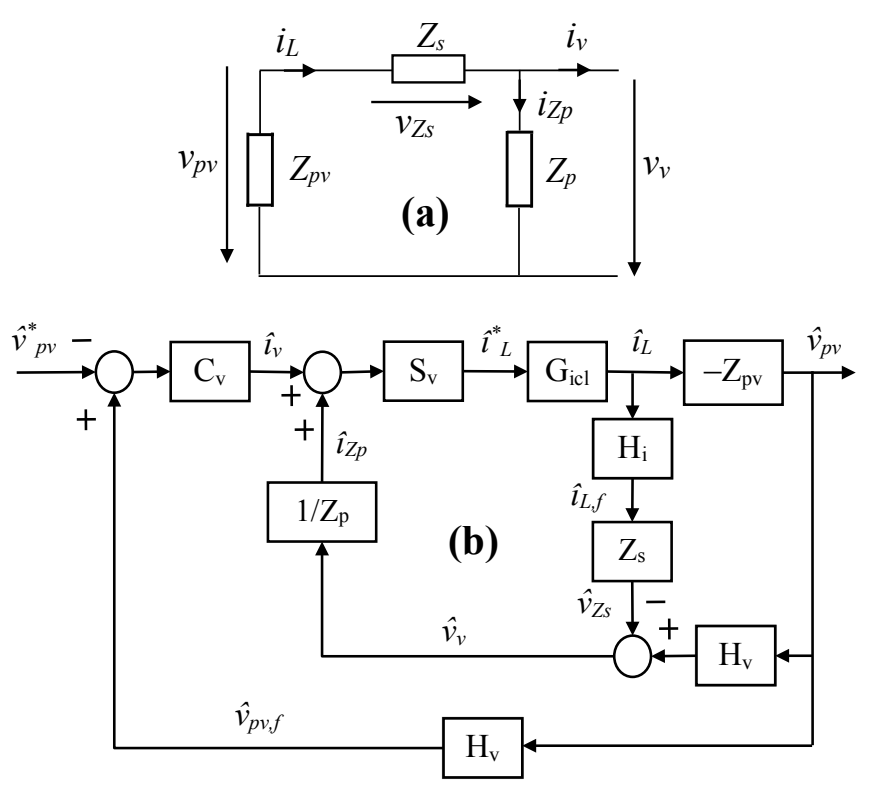

Fig. 14. PV voltage control with SPIE: (a) ideal equivalent circuit, (b) PV voltage control loop.

Thus, assuming ideal emulation, the impedance seen by the controller is known and constant, making it possible to achieve a PV voltage control which is completely independent of the dynamic resistance.
For ease of implementation, let us choose resistive impedances, i.e. $Z_{p}=R_{p}$ and $Z_{s}=-R_{s}$, where $R_{p}>0$ and $R_{s}>0$. Then, the impedance implementation is as simple as calculating the reference current as

$$
i_{L}^{*}=i_{v}+\frac{1}{R_{p}} \cdot v_{p v, f}+\frac{R_{s}}{R_{p}} \cdot i_{L, f} .
$$

After selecting a certain $R_{s}$ value, since resistance $R_{p}$ is located in the feedback path [see Fig. 14(b) and (13)], its minimum value is limited in order to avoid RHP poles in equivalent impedance $Z_{e q}$. This constraint is equivalent to the one presented in section IV.B and can also be addressed using the generalized Bode criterion, now applied to the corresponding open loop Bode plot $S_{v} \cdot G_{i c l}\left(H_{v} \cdot Z_{p v}+H_{i} \cdot Z_{S}\right)$. For example, for a series resistance $R_{s}=3.5 \Omega$, a virtual resistance $R_{p}>2.99 \Omega$ is required to ensure stability. As a result, $R_{p}=R_{s}=3.5 \Omega$ could be chosen, making it possible to fulfill (15) and thus ideally remove the entire influence of dynamic resistance $R_{p v}$. However, in order to guarantee a higher gain margin, $R_{p}=3.8 \Omega$ is selected.

For the selected virtual impedances, $Z_{s}=-R_{s}=-3.5 \Omega$, and $Z_{p}=R_{p}=3.8 \Omega$, the equivalent impedance is plotted in Fig. 15 for the ideal case where $Z_{e q}=R_{p}$, and for three different operating points $\left(R_{p v}=1 \Omega, R_{p v}=10 \Omega\right.$ and $\left.R_{p v}=100 \Omega\right)$. As can be observed, thanks to the impedance emulation, the $Z_{e q}$ variation range around the crossover frequency is now very small, from $2.4 \Omega$ at OCV to $3.9 \Omega$ below MPP.

The voltage controller $C_{v}$ is of the same type as the one in the previous section, as shown in (12). Its parameters are designed to obtain a crossover frequency $f_{c v}=60 \mathrm{~Hz}$ for $R_{p v}=100 \Omega$ and a phase margin $\Phi_{m v}=50^{\circ}$ for $R_{p v}=1 \Omega$. The compensated open-loop is shown in Fig. 16, where it can be observed that the crossover frequency is almost constant for all operating points, with a variation ranging from 42 to $60 \mathrm{~Hz}$ (only 1.4 times).

As carried out in sections IV.A and IV.B, simulation results are presented here for the proposed control with SPIE. As can be observed in Fig. 17, the voltage response is very fast for the whole operating range, including very small $R_{p v}$ values. When comparing these results with the traditional control (see Fig. 8) and the proposed control with PIE (see Fig. 13), it is clear that the control performance has been greatly improved.

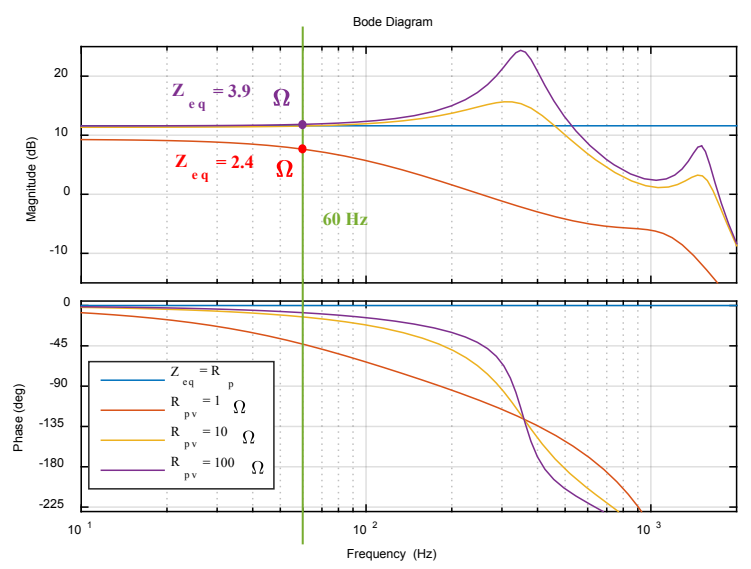

Fig. 15. Equivalent impedance seen by the voltage controller with SPIE, $Z_{e q}$, for the ideal case where $Z_{e q}=R_{p}$ and for three different operating points $\left(R_{p v}=1 \Omega, R_{p v}=10 \Omega\right.$ and $\left.R_{p v}=100 \Omega\right)$. 


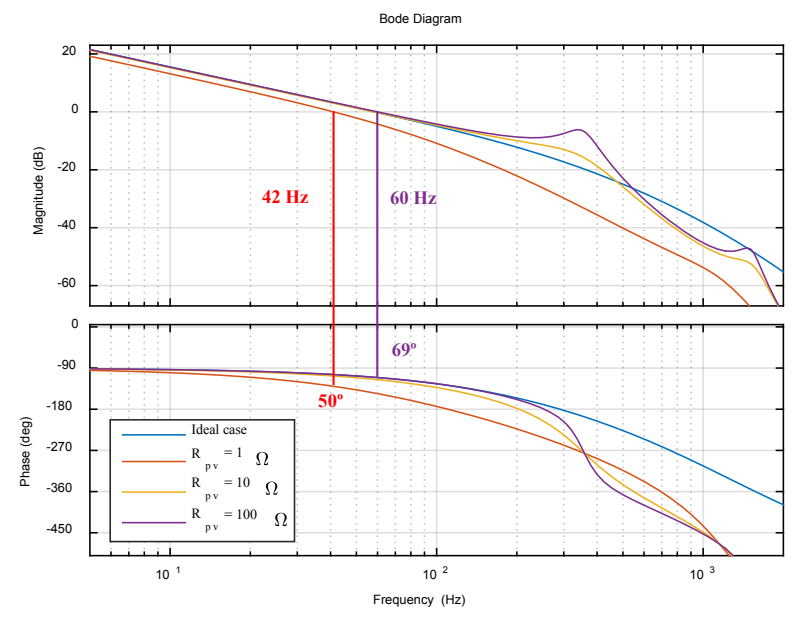

Fig. 16. Compensated open loop for the PV voltage regulation with SPIE, $C_{v} \cdot Z_{e q} \cdot H_{v}$, for the ideal case where $Z_{e q}=S_{v} \cdot R_{p}$ and for three different operating points $\left(R_{p v}=1 \Omega, R_{p v}=10 \Omega\right.$ and $\left.R_{p v}=100 \Omega\right)$.

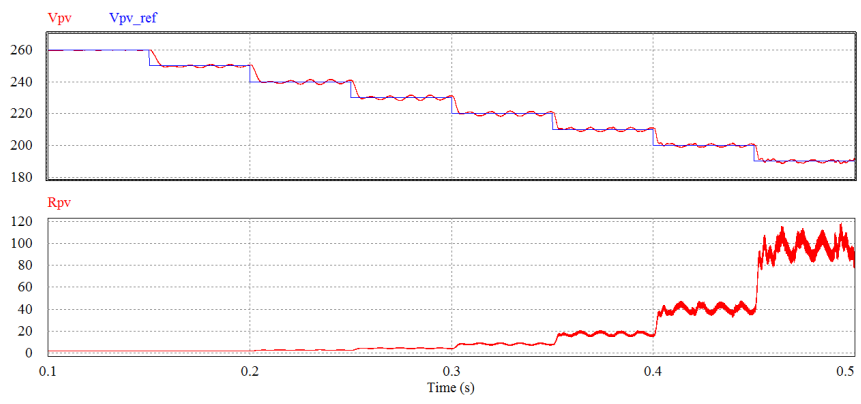

Fig. 17. Simulation of the PV voltage regulation for the proposed control with SPIE.

\section{Comparison among Voltage Regulations}

In this section, the following four voltage regulation are compared: traditional control, control of [25], proposed control with PIE and proposed control with PSIE.

The implementation of these regulations is shown in Fig. 18. Figure 18(a) shows the scheme for the traditional control, where $\mathrm{C}_{\mathrm{v}}$ is a PI controller, and Fig. 18(b) represents the scheme for the impedance-emulation-based methods, where $R_{s} \neq 0$ for $\mathrm{SPIE}, R_{s}=0$ for PIE and [25], and $\mathrm{C}_{\mathrm{v}}$ is the controller shown in (12). As it can be observed in the figure, if compared to the traditional control, impedance-emulation-based methods remain simple when resistances are selected as virtual impedances.

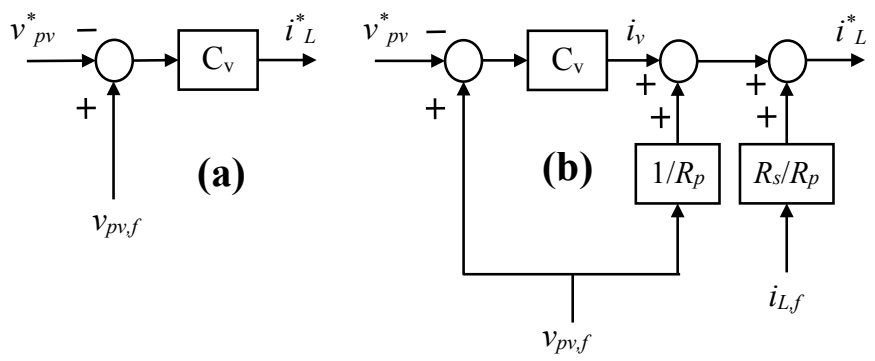

Fig. 18. Implementation of the voltage regulations: (a) traditional control, (b) impedance-emulation-based methods $\left(R_{s} \neq 0\right.$ for SPIE, $R_{s}=0$ for PIE and [25]).
Figure 19 shows the robustness assessment for the four regulations, where the crossover frequency is represented as a function of the dynamic resistance $R_{p v}$, from 0.5 to $500 \Omega$. In all cases, the controller has been designed to obtain a crossover frequency of $60 \mathrm{~Hz}$ for $R_{p v}=100 \Omega$. The dynamic variability improvement is clear from one control to another, where the traditional control presents the greatest variation, followed by the control of [25], the control with PIE and then the control with SPIE.

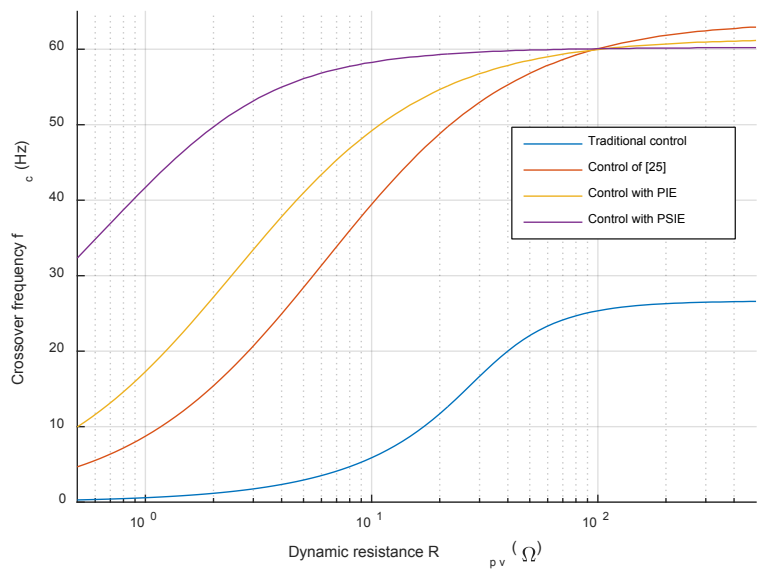

Fig. 19. Crossover frequency as a function of the dynamic resistance $R_{p v}$ for four different voltage regulations.

Additionally, the rise times obtained by simulation are compared for the four voltage regulations and are shown in Table III. The selected operating points are $R_{p v}$ around $2.3 \Omega$ (near OCV), $R_{p v}$ around $10 \Omega$ (near MPP) and $R_{p v}$ around $100 \Omega$ (below MPP). Once again, it is confirmed that the control with SPIE achieves high robustness for the whole operating range, followed by the control with PIE, then the control of [25], and the traditional control, where the dynamic variability is enormous. Thus, thanks to the proposed methods, the MPPT controller period can be considerably reduced, which leads to an improvement in the MPPT efficiency [31], [32]. On account on the analysis of [31] for the stabilization time, the traditional control requires an MPPT cycle of about $500 \mathrm{~ms}$, whereas the proposed control with SPIE can reduce this time up to about $10 \mathrm{~ms}$.

TABLE III

RISE TIMES OF THE FOUR CONTROLS FOR THREE DIFFERENT OPERATING POINTS

\begin{tabular}{cccc}
\hline \hline & $R_{p v} \approx 2.3 \Omega$ & $R_{p v} \approx 10 \Omega$ & $R_{p v} \approx 100 \Omega$ \\
\hline Traditional control & $340 \mathrm{~ms}$ & $61 \mathrm{~ms}$ & $9.8 \mathrm{~ms}$ \\
Control of [25] & $22 \mathrm{~ms}$ & $8.6 \mathrm{~ms}$ & $4.0 \mathrm{~ms}$ \\
Proposed control with PIE & $11 \mathrm{~ms}$ & $6.2 \mathrm{~ms}$ & $3.9 \mathrm{~ms}$ \\
Proposed control with SPIE & $6.6 \mathrm{~ms}$ & $5.1 \mathrm{~ms}$ & $4.1 \mathrm{~ms}$ \\
\hline \hline
\end{tabular}

\section{EXPERIMENTAL RESULTS}

The experimental setup is shown in Fig. 20, where a commercial two-stage 5-kW PV inverter is used. The first stage is a boost converter with features shown in Table I, and its input is connected to the PV array shown in the figure, with features presented in Table II. The second stage is a single-phase inverter which is connected to the grid. Precision power 
analyzer WT3000 served to obtain the data, supplying voltages and currents every $100 \mu \mathrm{s}$. During the tests, the irradiance was close to $900 \mathrm{~W} / \mathrm{m}^{2}$ and the cell temperature was around $58^{\circ} \mathrm{C}$, leading to $V_{o c} \approx 220 \mathrm{~V}$ and $V_{m p p} \approx 176 \mathrm{~V}$.

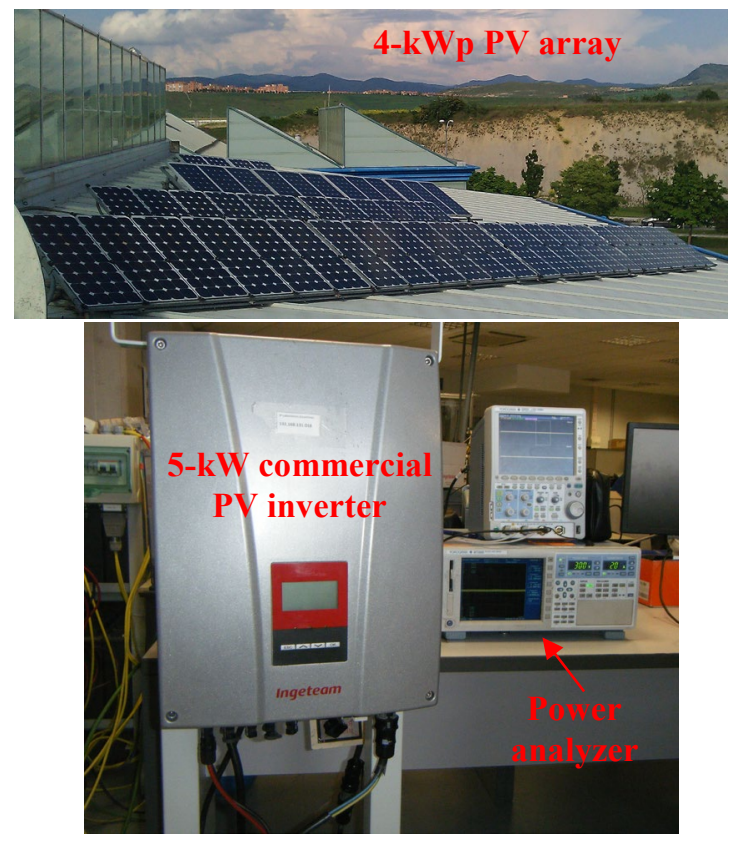

Fig. 20. Experimental setup.

Three PV voltage control techniques are compared, in all cases maintaining the inner current control presented in section III. The first one represents the original configuration of the converter, where the PI controller is designed without taking into account the PV array effect (presented in section IV.A). Then, the converter configuration is modified in order to implement the proposed controls: PIE with $R_{p}=3 \Omega$ (presented in section IV.B) and SPIE with $R_{s}=3.5 \Omega$ and $R_{p}=3.8 \Omega$ (in section IV.C). Figure 21 shows the PV voltage and current in response to downward steps in the voltage reference from $214 \mathrm{~V}$, close to OCV, to $162 \mathrm{~V}$, below the MPP voltage. It can be observed that the traditional control is very slow and variable depending on the operating point. On the contrary, both proposed controls are much faster for the whole operating range.

In order to make a better comparison, the voltage response of the three regulations can be drawn together, as carried out in Fig. 22 for $R_{p v}$ around $2.3 \Omega$, close to OCV. It is clear from the figure that both proposed methods improve the voltage response, especially the control with SPIE. Although not represented here for space reasons, similar voltage reference steps were applied close to MPP, with $R_{p v}$ around $10 \Omega$, and below MPP, with $R_{p v}$ around $100 \Omega$. From these tests, the approximate rise times were obtained and are shown in Table IV. When comparing these times, it should be considered that the dynamic resistance depends on the voltage operating point but also on ambient conditions, so it is difficult to reproduce the exact same transient. In any case, these results are in accordance with the ones obtained by simulation (see Table III). In summary, the results confirm the previous analyses, showing that: (a) the traditional control is strongly affected by the PV array at all operating points, (b) the proposed control with PIE is much faster and more robust, although a small dependence on the dynamic resistance is observed near $\mathrm{OCV}$, and (c) the proposed control with SPIE is practically independent of the dynamic resistance for the whole operating range. As a result, on account of their performance and simplicity of implementation, both proposed methods are totally suitable to be used in a PV system.
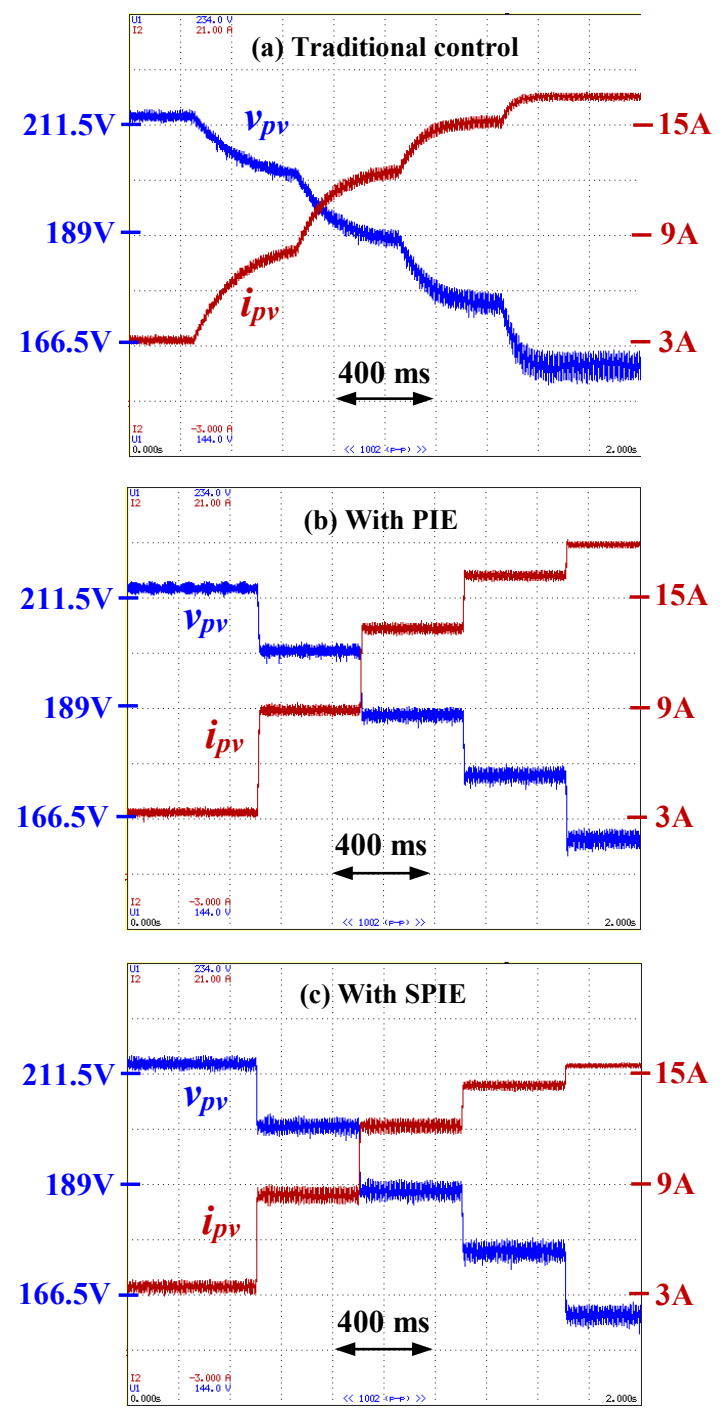

Fig. 21. Experimental results for the PV voltage regulation: (a) traditional control, (b) with PIE, (c) with SPIE.

\section{CONCLUSION}

In this paper, the voltage control of a PV array interfacing a current-mode-controlled boost converter is analyzed. It is first shown that, when only a PI controller is used, the voltage response is highly dependent on dynamic resistance and is very slow near open-circuit. In order to improve the robustness, a virtual impedance is emulated at the PV array terminals. This makes it possible to reduce the impedance variability seen by the voltage controller and, as result, a very fast and parameterindependent regulation is achieved. 


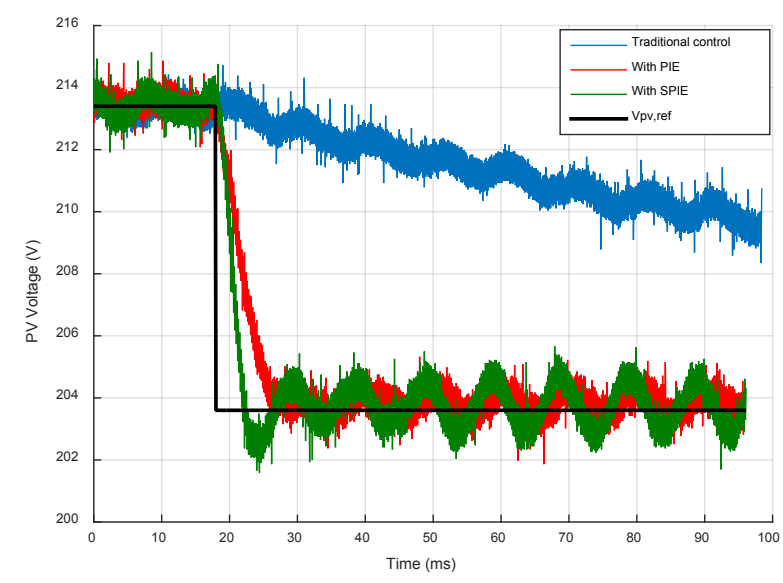

Fig. 22. $\mathrm{PV}$ voltage regulation close to $\mathrm{OCV}\left(R_{p v}\right.$ around $\left.2.3 \Omega\right)$ for the traditional control, the control with PIE and the control with SPIE.

TABLE IV

RISE TIMES OF THE THREE CONTROLS FOR THREE DIFFERENT OPERATING POINTS

\begin{tabular}{cccc}
\hline \hline & $R_{p v} \approx 2.3 \Omega$ & $R_{p v} \approx 10 \Omega$ & $R_{p v} \approx 100 \Omega$ \\
\hline Traditional control & $320 \mathrm{~ms}$ & $70 \mathrm{~ms}$ & $5.9 \mathrm{~ms}$ \\
Control with PIE & $8.3 \mathrm{~ms}$ & $4.4 \mathrm{~ms}$ & $3.7 \mathrm{~ms}$ \\
Control with SPIE & $4.0 \mathrm{~ms}$ & $4.0 \mathrm{~ms}$ & $3.7 \mathrm{~ms}$ \\
\hline \hline
\end{tabular}

A virtual impedance in parallel to the PV array is simple to implement, especially in the case of parallel resistance emulation. With this method, it is possible to greatly reduce the dynamic resistance influence. However, since the minimum impedance value is constrained due to stability issues, a small influence at low dynamic resistance values remains. Then, the parallel impedance-based strategy is combined with the emulation of an impedance in series with the PV array. This strategy is again very simple to implement when emulating two resistances and achieves a constant response for the whole operating range.

Simulation and experimental results concur and confirm that the proposed controls are fast and robust. The choice between parallel emulation or series and parallel impedance emulation should be determined by the designer based on the robustness required by the particular application.

\section{ACKNOWLEDGMENT}

The authors gratefully acknowledge the financial and ongoing support of INGETEAM POWER TECHNOLOGY.

\section{REFERENCES}

[1] R. Kadri, J. Gaubert, and G. Champenois, "An improved maximum power point tracking for photovoltaic grid-connected inverter based on voltageoriented control," IEEE Trans. Ind. Electron., vol. 58, no. 1, pp. 66-75, 2011.

[2] B.-R. Peng, K.-C. Ho, and Y.-H. Liu, "A novel and fast MPPT method suitable for both fast charging and partially shaded conditions," IEEE Trans. Ind. Electron., vol. 65, no. 4, pp. 3240-3251, 2018.

[3] A. M. S. Furtado, F. Bradaschia, M. C. Cavalcanti, and L. R. Limongi, "A reduced voltage range global maximum power point tracking algorithm for photovoltaic systems under partial shading conditions," IEEE Trans. Ind. Electron., vol. 65, no. 4, pp. 3252-3262, 2018.

[4] V. A. K. Pappu, B. Chowdhury, and R. Bhatt, "Implementing frequency regulation capability in a solar photovoltaic power plant," in 2010 North American Power Symposium (NAPS), pp. 1-6, 2010.
[5] A. Urtasun, P. Sanchis, and L. Marroyo, "Limiting the power generated by a photovoltaic system," in $10^{\text {th }}$ Multi-Conference on Systems, Signals and Devices (SSD), pp. 1-6, 2013.

[6] A. Sangwongwanich, Y. Yang, and F. Blaadjerg, "High-performance constant power generation in grid-connected PV systems," IEEE Trans. Power Electron., vol. 31, no. 3, pp. 1822-1825, 2016.

[7] J. Viinamaki, J. Jokipii, T. Messo, T. Suntio, M. Sitbon, and A. Kuperman, "Comprehensive dynamic analysis of photovoltaic generator interfacing DC-DC boost power stage," IET Renew. Power Gen., vol. 9, no. 4, pp. 306-314, 2015.

[8] J. Thongprona, K. Kirtikara, and C. Jivacate, "A method for the determination of dynamic resistance of photovoltaic modules under illumination," Solar Energy Mat. Solar Cells, vol. 90, no. 18-19, pp. 3078-3084, 2006.

[9] S. M. Tayebi, and I. Batarseh, "Mitigation of current distortion in a threephase microinverter with phase skipping using a synchronous sampling dc-link voltage control," IEEE Trans. on Ind. Electron., vol. 65, no. 5, pp. 3910-3920, 2018.

[10] A. Urtasun, and D. D. C. Lu, "Control of a single-switch two-input buck converter for MPPT of two PV strings," IEEE Trans. on Ind. Electron., vol. 62, no. 11, pp. 7051-7060, 2015.

[11] L. Qin, S. Xie, M. Hu, and C. Yan, "Stable operation area of photovoltaic cells feeding DC-DC converter in output voltage regulation mode," IET Renew. Power Gen., vol. 9, no. 8, pp. 970-981, 2015.

[12] M. G. Villalva, T. G. de Siqueira, and E. Ruppert, "Voltage regulation of photovoltaic arrays: Small-signal analysis and control design," IET Power Electron., vol. 3, no. 6, pp. 869-880, 2010.

[13] W. Xiao, W. G. Dunford, P. R. Palmer, and A. Capel, "Regulation of Photovoltaic Voltage," IEEE Trans. Ind. Electron., vol. 54, no. 3, pp. 1365-1374, 2007.

[14] L. Nousiainen el al., "Photovoltaic generator as an input source for power electronic converters," IEEE Trans. Power Electron., vol. 28, no. 6, pp. 3028-3038, 2013.

[15] A. Urtasun, P. Sanchis, and L. Marroyo, "Adaptive voltage control of the $\mathrm{dc} / \mathrm{dc}$ boost stage in PV converters with small input capacitors," IEEE Trans. Power Electron., vol. 28, no. 11, pp. 5038-5048, 2013.

[16] M. Sitbon, S. Schacham, T. Suntio, and A. Kuperman, "Improved adaptive input voltage control of a solar array interfacing current mode controlled boost power stage," Energy Conv. and Manag., vol. 98, pp. 369-375, 2015.

[17] L. V. Bellinaso, R. P. Vieira, H. A. Grundling, and L. Michels, "Adaptive control of PV boost converter for minimal passive components and fast maximum power point tracking," in $11^{\text {th }}$ IEEE/IAS Intern. Conf. on Ind. Appl. (INDUSCON), pp. 1-7, 2014.

[18] M. Sitbon, S. Schacham, and A. Kuperman, "Disturbance observer-based voltage regulation of current-mode-boost-converter-interfaced photovoltaic generator," IEEE Trans. Ind. Electron., vol. 62, no. 9, pp. 5776-5785, 2015.

[19] R. Errouissi, A. Al-Durra, and S. M. Muyeen, "A robust continuous-time MPC of a DC-DC boost converter interfaced with a grid-connected photovoltaic system," IEEE Journal of Photovoltaics, vol. 6, no. 6, pp. 1619-1629, 2016

[20] M. Wu, and D. D.-C. Lu, "Adding virtual resistance in source side converters for stabilization of cascaded connected two stage converter systems with constant power loads in DC microgrids," in 2014 Int. Power Electron. Conference (IPEC), pp. 3553-3556, 2014.

[21] Y. Huangfu, S. Pang, B. N. Mobarakeh, L. Guo, A. K. Rathore, and F. Gao, "Stability analysis and active stabilization of on-board DC power converter system with input filter," IEEE Trans. Ind. Electron., vol. 65, no. 1, pp. 790-799, 2018.

[22] X. Wang, Y. W. Li, F. Blaadjerg, and P. C. Loh, "Virtual-impedancebased control for voltage-source and current-source converters," IEEE Trans. Power Electron., vol. 30, no. 12, pp. 7019-7037, 2015.

[23] A. Urtasun, A. Berrueta, P. Sanchis, and L. Marroyo, "Parameterindependent control for battery chargers based on virtual impedance emulation," IEEE Trans. Power Electron., early access, 2017.

[24] A. Urtasun, P. Sanchis, and L. Marroyo, "Parameter-independent battery voltage control based on virtual capacitor emulation," in Intern. Exhibition and Conf. for Power Electron., Intelligent Motion, Renew. Energy and Energy Manag. (PCIM), pp. 1209-1216, 2016.

[25] A. Urtasun, P. Sanchis, and L. Marroyo, "Control of a photovoltaic array interfacing current mode controlled boost converter based on virtual resistance emulation," in $42^{\text {nd }}$ Annual Conf. of the IEEE Ind. Electron. Society (IECON), pp. 3046-3051, 2016. 
[26] K. De Gusseme, D. M. Van de Sype, A. P. M. Van den Bossche, and J. A. Melkebeek, "Digitally controlled boost power-factor-correction converters operating in both continuous and discontinuous conduction mode," IEEE Trans. Ind. Electron., vol. 52, no. 1, pp. 88-97, 2005.

[27] J. L. Agorreta, M. Borrega, J. López, and L. Marroyo, "Modeling and control of N-paralleled grid-connected inverters with LCL filter coupled due to grid impedance in PV plants," IEEE Trans. Power Electron., vol. 26, no. 3, pp. 770-785, 2011.

[28] R. Kadri, J. Gaubert, and G. Champenois, “An improved maximum power point tracking for photovoltaic grid-connected inverter based on voltageoriented control," IEEE Trans. Ind. Electron., vol. 58, no. 1, pp. 66-75, 2011.

[29] J. L. Agorreta, L. Reinaldos, R. González, M. Borrega, J. Balda, and L. Marroyo, "Fuzzy switching technique applied to PWM boost converter operating in mixed conduction mode for PV systems," IEEE Trans. Ind. Electron., vol. 56, no. 11, pp. 4363-4373, 2009.

[30] D. Lumbreras, E. L. Barrios, A. Ursúa, L. Marroyo, and P. Sanchis, "On the stability criteria for inverter current control loops with LCL output filters and varying grid impedance," in $19^{\text {th }}$ European Conference on Power Electronics and Applications (EPE), pp. 1-10, 2017.

[31] E. Bianconi, J. Calvente, R. Giral, E. Mamarelis, G. Petrone, C. A. Ramos-Paja, G. Spagnuolo, and M. Vitelli, "A fast current-based MPPT technique employing sliding mode control," IEEE Trans. Ind. Electron., vol. 60 , no. 3, pp. 1168-1178, 2013.

[32] M. A. Ghasemi, A. Ramyar, and H. Iman-Eini, "MPPT method for PV systems under partially shaded conditions by approximating I-V curve," IEEE Trans. Ind. Electron., vol. 65, no. 5, pp. 3966-3975, 2018.

\section{BIOGRAPHIES}

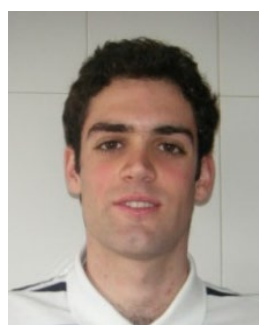

Andoni Urtasun (S'11-M'16) was born in Pamplona, Spain, in 1987. He received the M.Sc. degree in electrical engineering from the Public University of Navarre (UPNA), Pamplona, Spain, and from the Institut National Polytechnique de Toulouse, Toulouse, France, both in 2010, and the Ph.D. degree in electrical engineering from the UPNA in 2015.

In 2010, he joined the Electrical Engineering, Power Electronics and Renewable Energy research group, UPNA, where he is currently Assistant Professor. During 2014, he was visiting scholar in the University of Sydney, Australia. His research interests include power electronics and renewable energies.

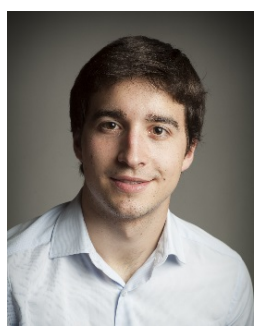

Javier Samanes (S'16) was born in Pamplona, Spain, in 1990. He received the M.Sc. degree in electrical engineering from the Public University of Navarre, Pamplona, Spain, in 2014 and the M.Sc. degree in renewable energy engineering in 2016 from the same institution. From 2013 to 2014 he was a researcher at CENER (Spanish National Renewable Energy Center) working on his master thesis.

In 2014, he joined the Electrical Engineering, Power Electronics and Renewable Energy Research Group at the Public University of Navarre, where he is currently working towards the Ph.D. degree. His research interests include power electronics and renewable energies.

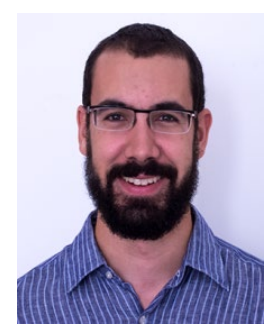

Ernesto L. Barrios (S'12-M'16) was born in Pamplona, Spain, in 1988. He received the B.Sc., M.Sc. and Ph.D. degrees in electrical engineering from the Public University of Navarre (UPNA), Pamplona, Spain, in 2009, 2012 and 2015, respectively.

In 2011, he joined the Electrical Engineering, Power Electronics and Renewable Energy research group (INGEPER), Public University of Navarre, where he is currently Assistant Professor. His main research interests include high frequency magnetics, wide bandgap power semiconductor devices and power converters for renewable energies, particularly for photovoltaics and fuel cells.

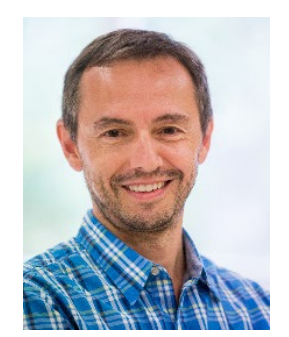

Pablo Sanchis (M'03-SM'12) received the M.Sc. and Ph.D. degrees in electrical engineering in 1995 and 2002, respectively, and the M.Sc. degree in management and business administration in 1994, all from the Public University of Navarre, Pamplona, Spain.

From 1996 to 1998, he worked as a Guest Researcher at Delft University of Technology, The Netherlands. In 1998, he joined the Department of Electrical, Electronic and Communications Engineering at the Public University of Navarre (UPNA), where he is currently Associate Professor. He is also Director of the UPNA Chair for Renewable Energies and Director of the Research Resources and Structures Unit of the university. Previously, he was Vice Dean of the School of Industrial and Telecommunications Engineering.

$\mathrm{He}$ has been involved in more than 70 research projects both with public funding and in co-operation with industry and is the co-inventor of 8 patents. He has also co-authored more than 140 papers and contributions in international journals and conferences, and supervised 9 PhD thesis. In 2013, he received the UPNA Research Award for the best technical paper and in 2017 he received the UPNA Excellence in Teaching Award. His research interests include renewable energies, power electronics, electric energy storage technologies, grid integration of renewable energies and electric microgrids.

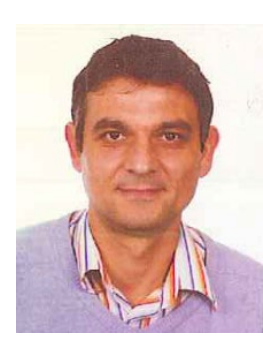

Luis Marroyo (M'04) received the M.Sc. degree in electrical engineering in 1993 from the University of Tolouse, France, and the Ph.D. degree in electrical engineering in 1997 from the UPNA, Spain, and in 1999 from the LEEIENSEEIHT INP Toulouse, France.

From 1993 to 1998, he was Assistant Professor at the Department of Electrical and Electronic Engineering of the UPNA, where he currently works as Associate Professor, since 1998. He is the head of the INGEPER research group. He has been involved in more than 60 research projects mainly, in co-operation with industry, he is the co-inventor of 15 international patents and co-authored of more than 100 papers in international journals and conferences. His research interests include power electronics, grid quality and renewable energy. 